\title{
UPACARA TUNGGUL WULUNG Pengembangan Wisata Tradisi ${ }^{1}$
}

\author{
Oleh \\ Suwarna \\ FBS UNY \\ suwarnadr@uny.ac.id
}

\section{Pendahuluan}

Tahun 2020 Yogyakarta menjadi pusat kebudayaan terkemuka. Itulah visi kebudayaan DIY. Yogyakarta sebagai daerah istimewa juga memiliki kebijakan bahwa 90\% anggaran keistimewaan akan diarahkan untuk pengembangan kebudayaan. Yogyakarta memang kaya budaya. Oleh karena itu, layak kalau Yogyakarta juga disebut kota budaya, selain sebagai kota pendidikan dan kota perjuangan.

Ada tiga ranah budaya yang harus dipahami, yakni budaya pikir, budaya perilaku, dan budaya material (Suwito, 2007). Budaya pikir terkait dengan pedoman hidup (way of life) manusia. Budaya perilaku terkait dengan ucap, sikap, gaya hidup, atau tindakan manusia dalam berperikehidupan. Pedoman hidup sangat mempengaruhi gaya hidup manusia. Budaya material terkait dengan benda-benda material sebagai hasil karya manusia. Pedoman hidup merupakan budaya yang tankasat mata (intangible), sedangkan budaya perilaku dan material bersifat kasat mata (tangible).

Yogyakarta sebagai kota budaya memiliki tiga ranah budaya tersebut, baik yang bersifat tangible maupun intangible. Ketiga ranah budaya tersebut saling mempengaruhi dan berkolaborasi membentuk satu kesatuan budaya, yakni budaya Yogyakarta. Budaya Yogyakarta pun banyak ragamnya. Salah satu ragam budaya itu adalah upacara tradisional atau upacara adat, sering disebut upacara adat tradisional. Salah satu contoh upacara adat tradisional adalah Upacara Tunggul Wulung di Desa Sendangagung, Kecamatan Minggir, Kabupaten Sleman. Oleh Dinas Kebudayaan dan Pariwisata Kabupaten Sleman, upacara Tunggul Wulung telah didaftarkan sebagai aset wisata yang perlu terus dikembangkan oleh

\footnotetext{
${ }^{1}$ Tulisan ini didasarkan dan dikembangkan dari Laporan Kegiatan KKN-PPM Mahasiswa UNY tahun 2009 dan penulis sebagai pembimbing DPL.
} 
pemangku dan penggiat budaya. Dinas Kebudayaan dan Pariwisata Kabupaten Sleman terus mengadakan pembinaan, pengembangan, dan pelestarian berbagai upacara adat (Supriyatno, 2008). Secara kebetulan, penulis juga pelaku dan penggiat budaya yang juga menjadi anggota Forum Kebudayaan Kabupaten Sleman.

Upacara Tunggul Wulung merupakan salah satu upacara adat tradisi di Kabupaten Sleman. Upacara ini semakin lama semakin berkembang. Perkembangan itu ditengarai dengan (1) kuantitas acara, (2) kuantitas pengunjung, (3) kualitas acara, (4) partisipasi warga dalam upacara, (5) kuantitas biaya, (6) omset ekonomis, (7) publikasi, dan (8) kuantitas pengunjung. Secara performansi dan kompleksitas, upacara Tunggul Wulung semakin berkembang setelah didukung oleh mahasiswa UNY yang melaksanakan KKN-PPM tahun 2009 dan di situ penulis sebagai pembimbing DPL KKN-PPM.

\section{Latar Belakang Tradisi Tunggul Wulung}

Raden Tunggul atau Ki Ageng Tunggul Wulung adalah putra Raden Sumirat atau Bhre Pandanalas, yaitu suami Bhre Singopuro dan Bhre Kahuripan. la lahir ketika Majapahit diperintah oleh Prabu Brawijaya III. Pada 1466-1468 Bhre Pandanalas memimpin Majapahit dan bergelar Prabu Brawijaya IV. Pada 1468-1478 Bhre Kertabumi memimpin kerajaan Majapahit, yang berarti singgasana kekuasaan kembali ke garis keturunan kerajaan. Bhre Kertabumi yang bergelar Prabu Brawijaya $\vee$ adalah putra Prabu Rajasa Wardana atau Brawijaya II.

Ketika Majapahit runtuh, Ki Ageng Tunggul Wulung melakukan perjalanan ke barat hingga Dusun Beji (Diro). Pada suatu malam, Jumat Pon, Ki Ageng Tunggul Wulung melakukan tirakat di bawah pohon Timoho di dekat Sungai Progo, diikuti oleh istrinya, pengawalnya, Nyai Dakiyah, serta binatang peliharaan kesayangannya, yakni burung perkutut, burung gemak, macan gembong, macan kumbang, macan putih, naga ijo, naga ireng, dan ayam jago wiring kuning. Dalam tirakat itu akhirnya Ki Ageng beserta mereka yang ikut bertirakat mukswa (musnah beserta raganya atau hilang tanpa bekas).

Atas saran seorang Belanda kepada Nyai Kriyoleksono, Juru Kunci kedua petilasan Ki Ageng Tunggul Wulung, tempat mukswa Ki Ageng Tunggul Wulung 
dibuatkan nisan sebagai simbol layaknya makam. Dalam perkembangannya petilasan ini diyakini oleh masyarakat banyak sebagai tempat yang keramat atau wingid dan banyak orang berziarah ke makam tersebut. Sampai dewasa ini peristiwa Ki Tunggul Wulung dijadikan upacara tradisi yang disebut upacara Adat Tunggul Wulung (KKN-PPM UNY, Buku Sejarah Upacara Adat Tunggul Wulung, 2009).

\section{Pengembangan Tradisi}

Untuk dapat menjadi aset wisata yang menarik, upacara Tunggul Wulung perlu dikemas, ditingkatkan performansinya, dan dipublikasikan. Beberapa pengembangan yang dilakukan oleh mahasiswa bersama tokoh dan masyarakat adalah (1) pembuatan Buku Sejarah Upacara Adat Tunggul Wulung, (2) pembuatan Buku Panduan Pelaksanaan Upacara Adat Tunggul Wulung, (3) dokumentasi visual dan audiovisual, (4) Publikasi Global (website) Upacara Adat Tunggul Wulung, (5) pembuatan buku Makna Busana Upacara Adat, (6) pembuatan Buku Panduan Wicara Bahasa Jawa, dan (7) pelatihan tari anak, dewasa, dan remaja (Laporan KKN-PPM, 2009).

Pembuatan Buku Sejarah Upacara Adat Tunggul Wulung perlu dilakukan agar ada pembakuan sejarahnya. Masyarakat Jawa terkenal dengan sebutan masyarakat tutur. Jangan sampai sejarah menjadi beraneka versi seiring berkembangnya bahasa lisan dan sebagai akibat penambahan dan pengurangan cerita. Dalam masyarakat Jawa dikenal peribahasa undhaking pawarta sudaning kiriman 'menambah atau mengurangi cerita'. Dengan adanya buku sejarah, cerita dapat didokumentasikan secara tertulis. Data-data untuk isi buku tersebut digali dengan wawancara mendalam kepada narasumber dan pelaku adat yang masih hidup. Pembukuan sejarah dirasakan penting sebelum kehilangan narasumber karena meninggal misalnya.

Buku Panduan Pelaksanaan Upacara Adat Tunggul Wulung merupakan acuan pelaksanan upacara adat Tunggul Wulung. Dengan buku panduan ini (1) segala kegiatan bersumber dari panduan yang sama, (2) kegiatan menjadi terorganisasi, dari perencanaan, pelaksanaan, hingga evaluasi, (3) taraf keberhasilan kegiatan memiliki acuan atau indikator yang jelas, (4) publikasi 
menjadi lebih mudah, dan (5) penggalian dana atau sponsorship juga lebih terpercaya.

Dokumentasi visual dan audiovisual merupakan upacara pendokumentasian secara elektronik. Dokumentasi visual berupa hasil-hasil fotografi dan dokumentasi audiovisual berupa dokumen video. Untuk dokumen video, selain cerita, juga diberi narasi dalam dua bahasa, yakni bahasa Indonesia dan bahasa Inggris, dalam bentuk teks berjalan di layar (running text). Sekitar dua minggu sebelum acara sudah ada keramaian berupa pasar malam dengan berbagai stand dagang ekonomi, makanan, pakaian, elektronik, sampai dengan motor. Dengan upacara tradisi Tunggul Wulung roda ekonomi menjadi bergairah. Berbagai transaksi ekonomi terjadi. Dengan demikian, upacara Tunggul Wulung dapat meningkatkan kesejahteraan masyarakat di Sendangagung. Di sisi lain, ditinjau dari segi psikologis, upacara Tunggul Wulung merupakan cara masyarakat bersyukur kepada Tuhan atas berbagai karunia nikmat berupa hasil-hasil pertanian, yang berdampak pada terjadinya ketenteraman jiwa.

Prosesi upacara, biasanya berlangsung Juli, acara diawali dengan pengambilan air suci Sendang Beji oleh tetua yang dikawal oleh prajurit Tunggul Wulung. Air dalam kendhi dibawa ke petilasan pertapaan Ki Ageng Tunggul Wulung. Pada hari berikutnya digelar keramaian aneka seni, seperti karawitan, tari, drama, dan musik. Pada pukul 13.00 kirab menuju Balai Desa Sendangagung dimulai, diikuti berbagai bregada (pleton) prajurit,

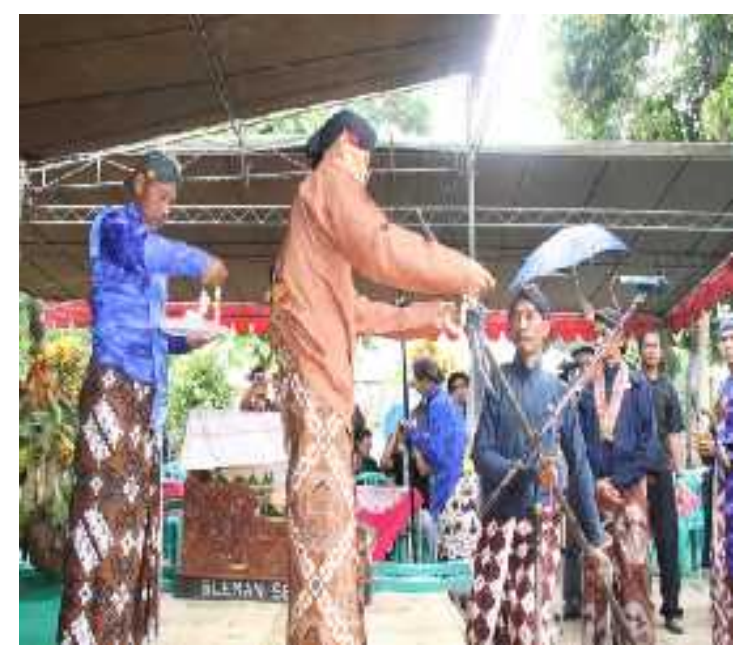

Gb. 1. Persiapan Kirab Tunggul Wulung

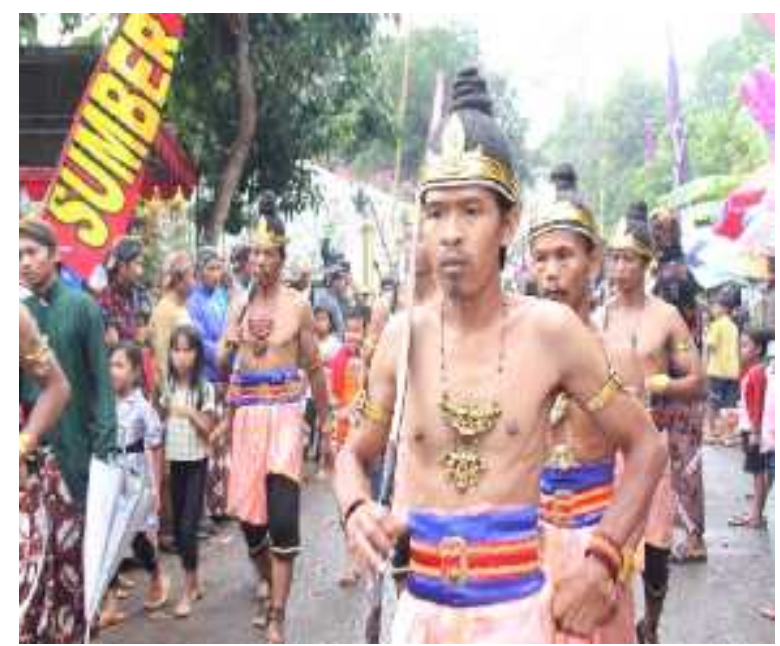

Gb. 2. Bregada Tunggul Wulung 
rata-rata dua belas bregada prajurit dengan pakaian yang berbeda-beda.

Berbagai hasil bumi yang disiapkan di Balai Desa Sendangagung segera dikirabkan menuju rumah petilasan pertapaan Ki Ageng Tunggul Wulung. Setelah dilakukan penyebaran udhik-udhik, berebut gunungan, acara kembali pada pementasan hiburan. Salah satu hiburan yang dianggap sakral adalah tari Tayub Gadhung Mlathi. Karena kesakralannya, notasi gending tari Tayub itu pun tidak boleh dituliskan, tetapi hanya boleh dihafalkan. Para niyaga langsung menabuh gamelan. Konon, tayub Gadhung Mlathi ini diibing (dipasangi penari) oleh $\mathrm{Ki}$ Ageng Tunggul Wulung sendiri. Pada malam harinya digelar wayang semalam suntuk.

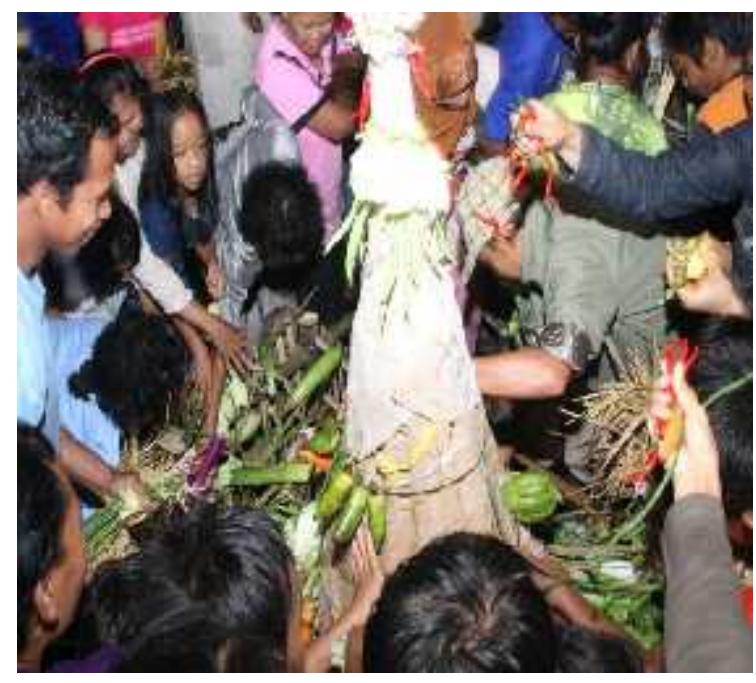

Gb. 3. Berebut Gunungan

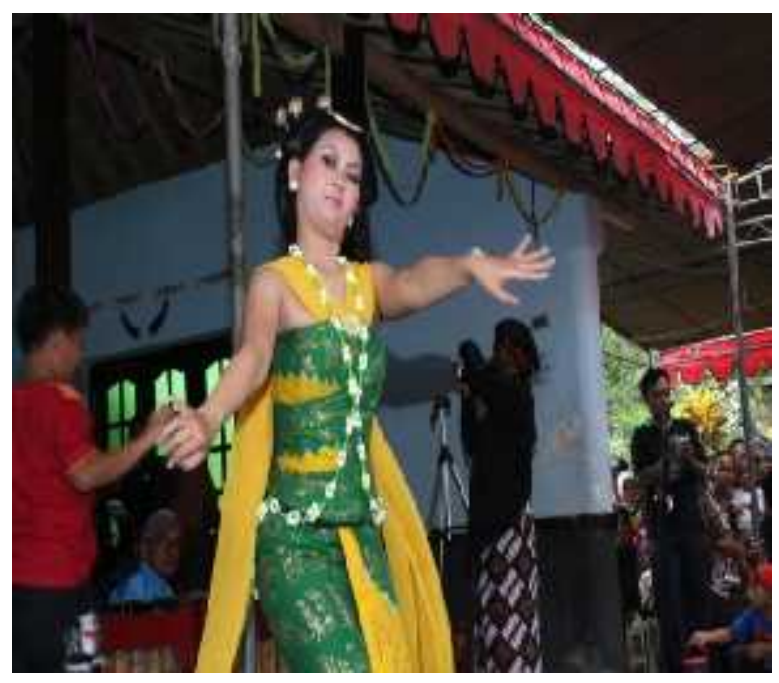

Gb. 4. Tari (Sakral) Tayub Gadung Mlati

Promosi upacara Adat Tunggul Wulung juga dilakukan melalui teknologi informasi seperti, jogjatv (http://new.jogjatv.tv/berita/22/09/2012/upacara-adattunggul-wulung), omahantz.blogspot.com/, bappeda.slemankab.go.id/, atau website-nya Dinas Kebudayaan dan Pariwisata Kabupaten Sleman (www.slemankab.go.id/200/kesenian-dan-kebudayaan.slm). Demikian juga, itu dipublikasikan melalui biro-biro traveling (pariwisata). Dengan cara itu, gaung upacara adat Kyai Tunggul Wulung menjadi semakin luas. 
Busana prajurit Tunggul Wulung juga perlu dibakukan dan dimaknai. Mahasiswa KKN-PPM UNY tahun 2009 telah berhasil menyusun buku Busana Prajurit Tunggul Wulung. Makna busana dideskripsikan dari atas (kuluk) hingga gelang kaki, demikian juga asesorisnya. Penyusunan buku busana dan maknanya merupakan salah satu upaya yang cukup berat karena itu merupakan sesuatu yang baru yang tidak ada sebelumnya. Penulis bersama mahasiswa kemudian berusaha mencari referensi dari buku sejarah, busana prajurit, dan berbagai narasumber. Dari situ dirumuskan nama dan makna busana prajurit Tunggul Wulung. Jika tidak ditemui referensi atau narasumber bakunya, tim penulis mulai bermain imajinasi dengan prinsip othak-athik mathuk, yakni 'memberikan nama dan makna yang selaras' didasarkan pada bentuk dan nama unsur busana, asesoris, dan ornamennya (KKN-PPM Buku Busana Prajurit Tunggul Wulung, 2009).

Panduan wicara pun dikembangkan sebagai sarana bagi masyarakat untuk belajar menjadi pembawa acara, pemberi sambutan, atau pidato. Dengan demikian, tugas pembawa acara dapat dilakukan secara bergantian. Selama itu kebutuhan akan pembawa acara dimintakan bantuan dari lain desa, yakni 'ngebon'. Panduan wicara yang disusun berdasarkan tata upacara dan tatacara, serta dituliskan dari kata per kata, diharapkan dapat menjadi sarana berajar menjadi pembawa acara. Kalau 'tata upacara' terkait dengan acara demi acara, tatacara terkait dengan segala alat piranti yang digunakan dalam upacara (makna filosofinya). Penulis (sebagai DPL) pun berkesempatan melatih para pemuda yang berminat menjadi pewara (pembawa acara).

Mahasiswa KKN-PPM juga melakukan pelatihan tari. Tari pendukung keramaian disiapkan untuk anak-anak dan remaja, tarinya cukup dinamis. Artinya, berkembang dari tari tradisional klasik hingga modern. Dengan adanya berbagai tari kreasi, upacara Tunggul Wulung semakin semarak dari tahun ke tahun, harapannya dapat dikunjungi oleh Bupati Sleman pada saat upacara berlangsung.

\section{Penutup}

Kebudayaan berkembang seiring dengan peradaban manusia. Budaya pikir, budaya perilaku, dan budaya material selalu melingkupi kehidupan manusia. Budaya perlu terus dikembangkan agar menjadi aset yang bermanfaat bagi 
kehidupan manusia. Upacara Adat Tunggul Wulung merupakan aset budaya yang dapat dikembangkan menjadi aset wisata budaya tradisional.

Yogyakarta merupakan 'kota budaya' yang kaya akan budaya tradisonal. Budaya sebagai aset wisata dapat dikembangkan dengan tiga cara, yakni (1) meningkatkan performansi (sajian budaya) agar selalu menarik wisatawan, (2) dokumentasi secara tertulis agar dapat dibaca publik, dan (3) publikasikan secara global melalui dunia maya.

DAFTAR PUSTAKA

KKN-PPM UNY. 2009. Buku Sejarah Upacara Tunggul Wulung. Yogyakarta: LPM. KKN-PPM UNY. 2009. Buku Busana Prajurit Tunggul Wulung. Yogyakarta: LPM. Supriyatno, Dwi. 2008. Selayang Pandang Upacara Adat di Kabupaten Sleman. Sleman: Dinas Kebudayaan dan Parisiwata Kabupaten Sleman.

Supriyatno, Dwi. 2008. Selayang Pandang Upacara Adat di Kabupaten Sleman.

Sleman: Dinas Kebudayaan dan Parisiwata Kabupaten Sleman.

Suwito, Yuwono Sri. 2007. Simbol-simbol Budaya dalam Kehidupan Masyarakat. Makalah. 